\title{
Data-Based Energy Efficient Clustered Routing Protocol for Wireless Sensors Networks - Tabuk Flood Monitoring System Case Study
}

\author{
https://doi.org/10.3991/ijes.v5i3.7529
}

Ammar E. Babiker, Mohamed A. A. Elmaleeh, Onaytra Abbas, Abdelrahman Osman Elfaki $\left.{ }^{\bowtie}\right)$ University of Tabuk, Tabuk, Saudi Arabia

a.elfaki@ut.edu.sa

\begin{abstract}
Energy efficiency has been considered as the most important issue in wireless sensor networks. As in many applications, wireless sensors are scattered in a wide harsh area, where the battery replacement or charging will be quite difficult and it is the most important challenge. Therefore, the design of energy saving mechanism becomes mandatory in most recent research. In this paper, a new energy efficient clustered routing protocol is proposed: the proposed protocol is based on analyzing the data collected from the sensors in a base-station. Based on this analysis the cluster head will be selected as the one with the most useful data. Then, a variable time slot is specified to each sensor to minimize the transmission of repetitive and un-useful data. The proposed protocol Data-Based Energy Efficient Clustered Routing Protocol for Wireless Sensors Networks (DCRP) was compared with the famous energy efficient LEACH protocol and also with one of the recent energy efficient routing protocols named Position Responsive Routing Protocol (PRRP). DCRP has been used in monitoring the floods in Tabuk area -Saudi Arabia. It shows comparatively better results.
\end{abstract}

\section{Introduction}

The recent development in sensors technology and communications media has steered to a wide use of sensors networks in many applications. Those applications include environmental monitoring, oil exploration, disaster alert system, flood monitoring and alerting system, and etc. [1-3].

Floods are considered as one of the severe disasters in the world. They have great effects on populations and properties. These effects are inversely proportional to the alerting time; therefore the design of monitoring and alerting system is of great importance in reducing losses and damages caused by floods [4-5].

The newly developed sensors are relatively small, inexpensive, and affordable for wide type of sensing such as temperature, flow, pressure, acoustic, level, etc. nevertheless still they have many limitations; the predominant is the one with the limited energy and computation capabilities [6-7].

Limited energy is the hot issue, which was discussed widely in the literature, and many different communications protocols in different layers were proposed and de- 
veloped. Consumption management, network layout, node distributions and management are among many other techniques, which were used in energy efficient protocols.

Generally, there are many scenarios in data collected by sensor nodes, but due to the computation limitation, the end point of data is usually a base station where there is no energy or computation constrains [8-9].

In this paper, the proposed protocol DCRP was studied as a case for flood monitoring and alerting system in Tabuk area. Yearly Tabuk is suffering from floods drain coming from many valleys (wadies) which originated from the mountains scattered around the city. The most severe one is called Wadi Dom which runs from the west towards Tabuk for more than $150 \mathrm{~km}$. It is selected as the case study in this work.

Wadi Dom root was divided into clusters. In each cluster, one of the nodes in a variable period was elected as cluster head to send the data to a node, which was laid in public mobile network coverage. This node in turns sends the data to the basestation.

\section{Related works}

Many topics in literature review regarding wireless sensors networks applications for flood monitoring and alerting system were proposed. Researchers use different mechanisms to analyze the collected data to provide useful information regarding flood. The following are examples of researches carried out throughout the past ten years.

One researcher proposed a combined wireless sensor networks and a data mining system to make early warning messages to smart and non-smart phones, data base are stored to help in forecasting and study future alerting [10].

Another research proposed an early warning system (EWS) to monitor data from a sensor networks in flood defenses such as embankments, dikes, levees and dams. Dike failure and breaching probability, predicated flood spreading and escape routes for people from affected area are calculated using real time information system and an artificial intelligence system. Results were presented in a decision support system to assist flood defense managers during flood events [11].

Kav K. Khed has proposed, designed and developed a real time flood monitoring system, which performs flood forecasting based on readily available data. A simple and fast calculation study for flood behavior was done [12].

A research group in Nigeria proposed and developed flood monitoring and detection system, which covers 15 flood prone regions in Uyo metropolis in Nigeria. The system incorporate a GIS map and sends flood notification SMS to the inhabitant of such zone for necessary action [13].

From the state of art it was observed that the above proposed protocols did not take energy consumptions into consideration, which is the most critical issue in WSNs. the majority of research in WSN was devoted to minimize energy consumption to prolong network lifetime 
According to Windi and others, conventional protocols of direct transmission, minimize transmission energy, multi-hop routing, and static clustering are not the optimal solution. They introduce a cluster-based routing protocol (LEACH), which select rotationally and randomly the cluster head to distribute the energy load among sensors. It also incorporate data fusion to reduce the amount of data transmitted [14].

Noor et.al proposed a Position Responsive Routing Protocol (PRRP) to minimize energy consumption in each node by [15]:

1. Reducing the listen state time by introducing time slot concept

2. Reducing the average communication distance in the network by incorporate energy calculation in cluster head selection.

A track sector clustering (TSC) scheme was proposed by the researcher Navin Gautum and others. In this scheme, the network is divided into centric circular tracks and triangular sectors to minimize redundant data transmission. The formation of tracks and sectors were carried out in the beginning of network setup [16].

Minch Tuan proposed a combination of Random Walk (RW) routing and a Comparative Sensing (CS) to save energy and prolong network lifetime. The mean value of the communication distance between sensors in a RW and the mean distance between RWs and the base station (BS) is formulated statically by exploit the minimum energy consumption for the network [17].

Finally Arati Manjeshwar and Dharape proposed a formal classification of sensor networks to proactive and reactive networks. Reactive networks respond immediately to changes in the relevant parameters of interest. They introduce a threshold sensitive energy efficient sensor networks (TEEN) for reactive networks. They also proposed a hybrid rooting and information retrieval protocol (APTEEN) [18].

In this protocol the node gives an overall picture of the network at aperiodic intervals in a very energy efficient manner besides reacting to time critical situations.

\section{Information Collection and Data Analysis}

Yearly Tabuk city suffered from severe floods coming from many valleys (wadies) around Tabuk as many hills and mountains surround the city. There are more than five dangerous wadies. The most dangerous one is Wadi Dom, which is more than 75 $\mathrm{km}$ long. Figure 1 shows wadies layout in Tabuk area, whereas Figure 2 shows a photo from 2010 flood [19-20]. 


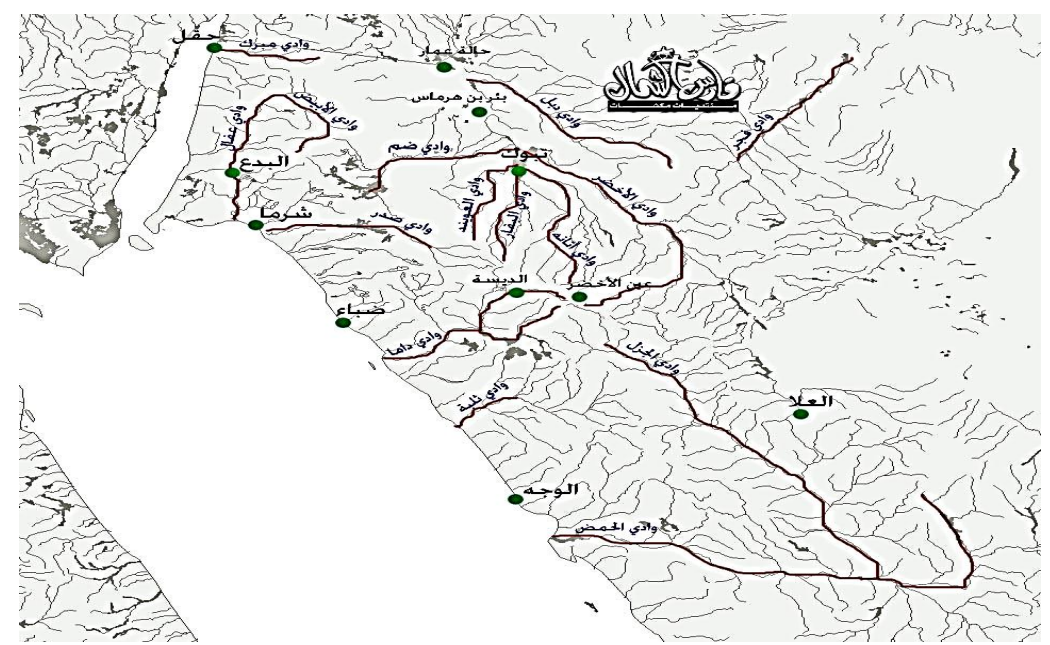

Fig. 1. Wadies layout in Tabuk area

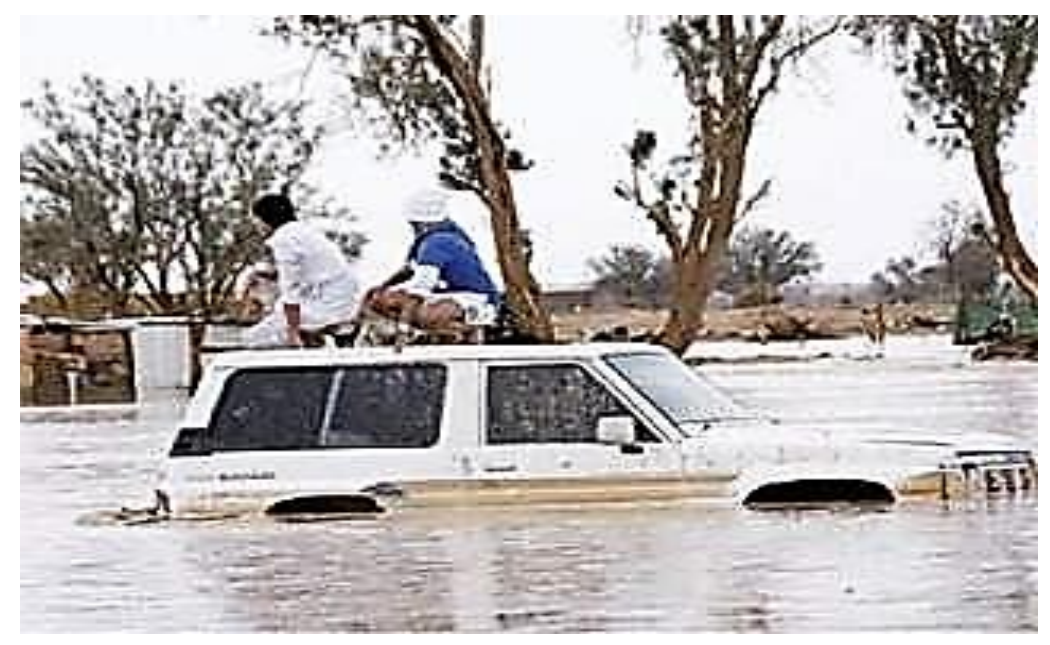

Fig. 2. Wadies layout in Tabuk area

\section{The proposed sensors network}

To design flood monitoring and alerting system for Wade Dom, the sensors are scattered in groups or clustered along the Wade. Figure 3 shows the block diagram of the proposed sensors network. For each group there will be a cluster head $(\mathrm{CH})$ which receive the data from the other members and send it to a base station device located in the near GSM network coverage. This GSM device in turns send the data to a centralized server in Tabuk through the GSM networks for data analysis and network management and alerting message distribution. Figure 3 shows Sensors Network Block Diagram. 


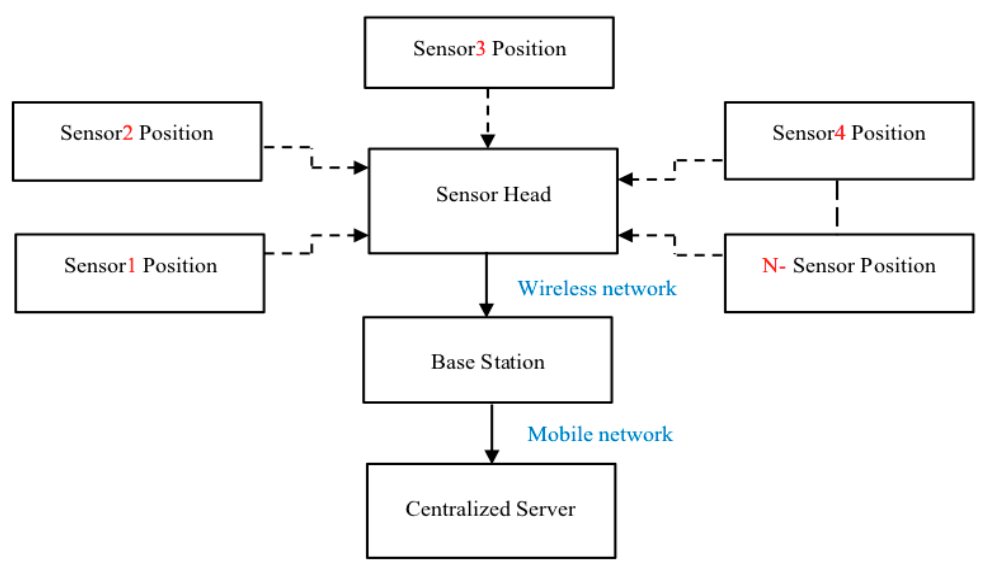

Fig. 3. Sensors Network Block Diagram

\section{Data-based energy efficient Clustered Routing Protocol (DCRP)}

The main interesting topic addressed in this proposed protocol is to enlarge the network lifetime by neglecting the repetitive and useless data. This neglecting is based on the previous data in a periodical fashion. The flow chart to describe the proposed DCRP is shown in Figure 4. The Network and data collection can be summarized as:

- Assume there are $\mathrm{n}$ cluster and in each cluster there are $\mathrm{m}$ sensors. The sensors were named $S(i, j)$ where $i=1: n$ and $m=1: j$.

- The data collected from the sensors represents the water flow rate and level. The flow rate and water level were referred to as $F(i, j)$ and $L(i, j)$.

Note: The data below some given value is considered useless as it will not cause flood and will not be transmitted.

- Average values of $F(i, j), L(i, j)$ were calculated as (Fa, La).

- All values $\{\mathrm{c}(\mathrm{i}, \mathrm{j})$ and $\mathrm{L}(\mathrm{i}, \mathrm{j})\}$ were compared with the average values and the deviations were calculated in percentages.

- In each cluster, the sensor in the group of sensors having the most repetitive value, and which laid in the center of that group was chosen as the cluster head for some time (round) or until a threshold value. This can be shown in the flowchart Figure 5 .

- In each period, if the data collected from the sensor is repeated the time slot from that sensor will be doubled until specific value (16 in our case); and if the data is changed the slot time will be reduced by half until 1 as shown in Figure 6 .

- This cycle of computation was repeated depending on stability of the information.

- \{Stable data means long cycle, and unstable values means short cycle) Whereas Figure 6 show the flowchart for cluster head (C.H.) selection. 
Paper-Data-Based Energy Efficient Clustered Routing Protocol for Wireless Sensors Networks

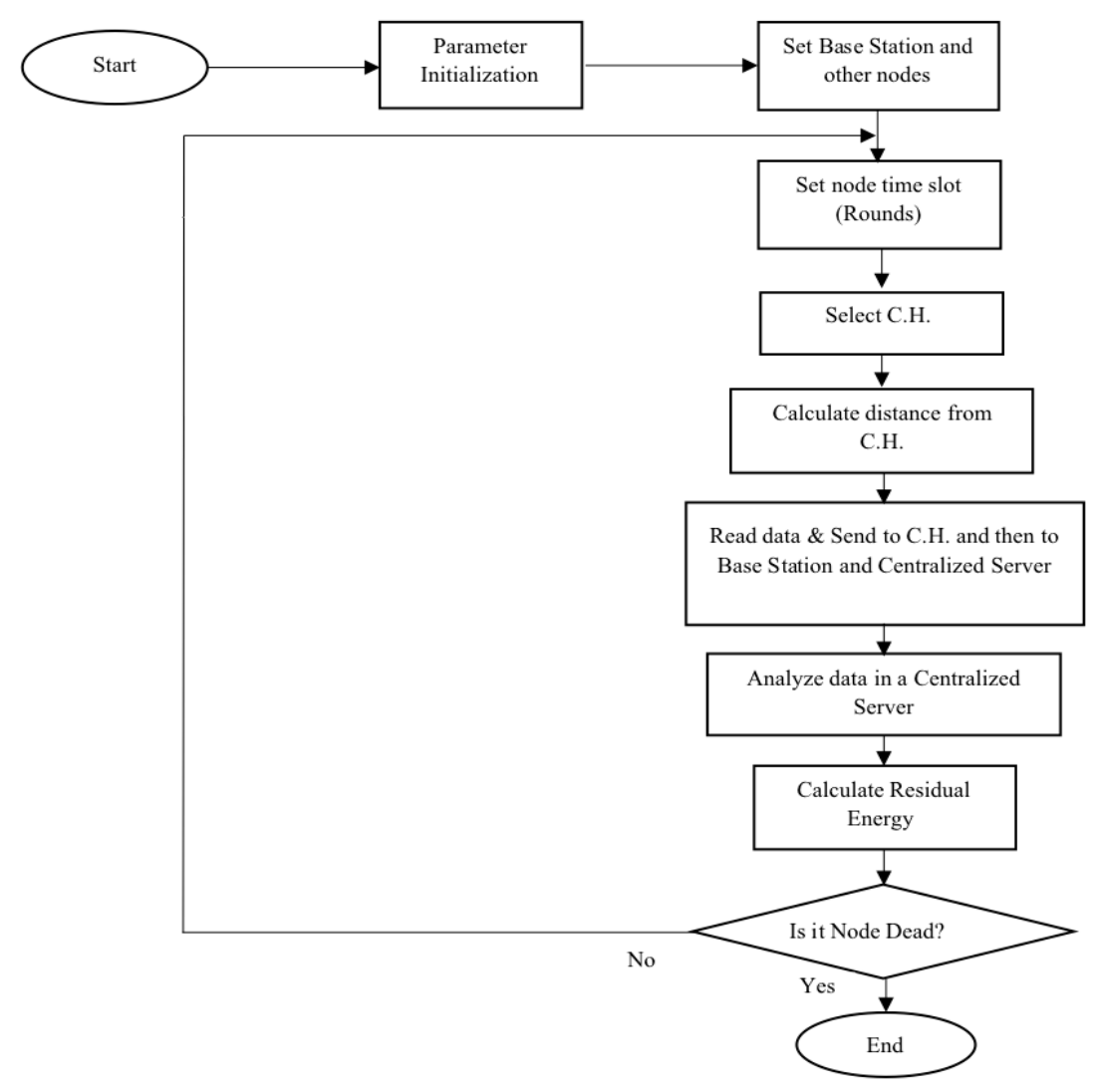

Fig. 4. DCRP flowchart

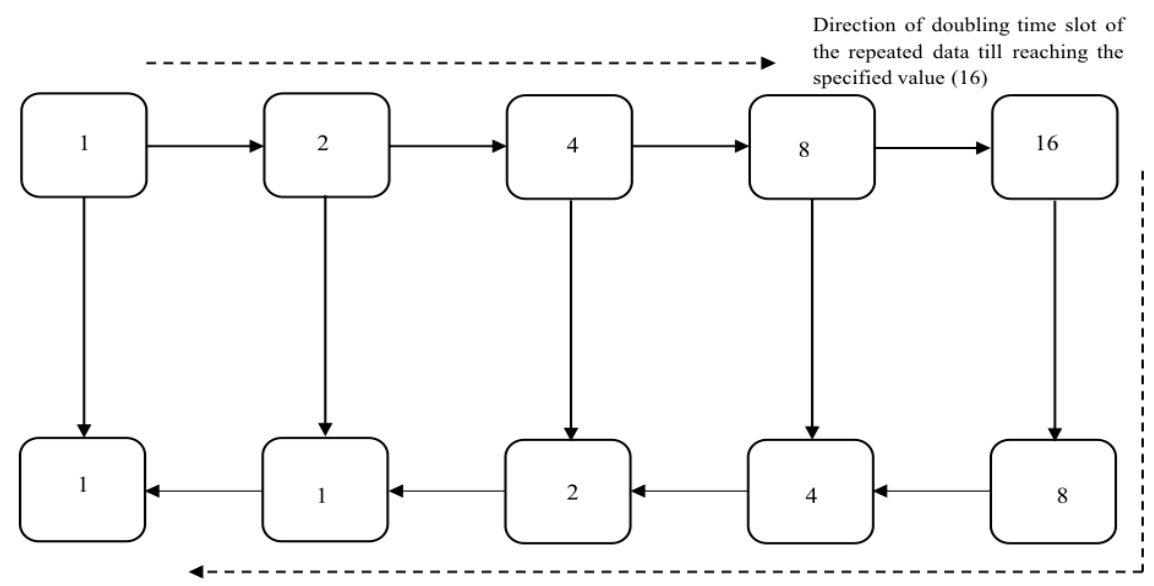

Direction of reducing the time slot by half for the unrepeated data till reaching 1

Fig. 5. Node time slot 


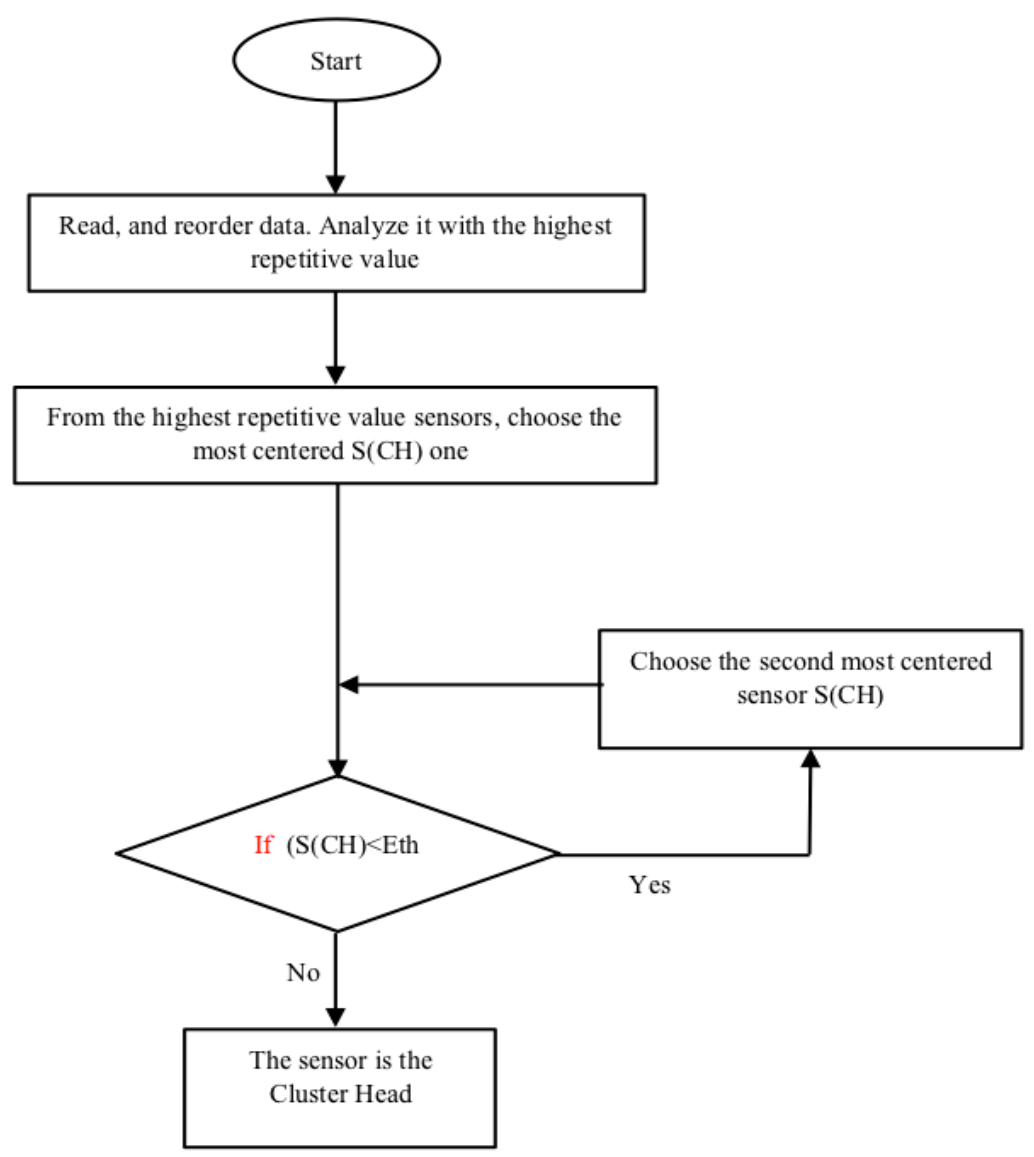

Fig. 6. Cluster Head (C.H.) selection flowchart

\section{Energy Calculations and simulation}

Sensor energy is consumed in transmitting, receiving data, computation or listening state. Transmission energy is based on the number of bits to be transmitted and the distance between the sender and receiver, whereas receiving energy depends on the number of bits only. Listening energy is usually fixed.

Transmission energy is calculated as in the following equations:

$$
\begin{gathered}
E(t x)=K E(\text { elec })+K E(\text { amp }) d \\
E(r x)=K E(\text { elec })
\end{gathered}
$$

Where $\mathrm{E}(\mathrm{elec})$ is the transceiver energy, $\mathrm{E}(\mathrm{amp})$ is the amplifier energy

In the DCRP proposed protocol no computation energy is needed as the computation is performed in a centralized server and only a management signal is send back to all sensors in a periodic fashion. This management signal determines the time slot for 
each sensor depending on previous data stability and analysis. i.e. in stable state the time slot is increased whereas it decreases when there is a change in the data. It also determines the suitable cluster head.

The DCRP proposed protocol is implemented Using Mat lab and is compared with both LEACH and PRRP protocols. The simulation environment parameters are shown in the following Table1:

Table 1. The simulation environment parameters [13]

\begin{tabular}{|c|l|l|}
\hline No. & \multicolumn{1}{|c|}{ Parameter } & \multicolumn{1}{|c|}{ Value } \\
\hline 1 & $X_{m}$ (X coordination) & 300 \\
\hline 2 & $Y_{m}$ (Y coordination) & 300 \\
\hline 3 & sink. $x$ (Base station x coordination) & $0.5 \times X_{m}$ \\
\hline 4 & sink. $y$ (Base station y coordination) & $0.5 \times Y_{m}$ \\
\hline 5 & $N$ (number of nodes) & 90 \\
\hline 6 & $P$ (Election Probability) & 0.1 \\
\hline 7 & $E_{O}$ (Initial energy) & 0.5 \\
\hline 8 & $E_{T X}$ (Transmission Cost) & $50 \times 10^{-9}$ \\
\hline 9 & $E_{R X}$ (receiving Cost) & $50 \times 10^{-9}$ \\
\hline 10 & $E_{F S}$ (energy dissipated per bit) & $10 \times e^{-12}$ \\
\hline 11 & $E_{M P}$ (energy dissipated per area) & $0.0013 \times e^{-12}$ \\
\hline 12 & $E_{D A}$ (Energy for data aggregation) & $5 \times 10^{-9}$ \\
\hline 13 & $R_{M A X}$ (Maximum number of rounds) & 2500 \\
\hline 14 & $d_{O}$ (Distance) & $\sqrt{E_{F S}}$ \\
\hline 15 & $E_{M P}$ (Transmission energy) & 0 \\
\hline
\end{tabular}

\subsection{Initialization stage}

At the initialization stage, the parameters shown in Table 1 are set to their initial value and the location of the base station is set to the central of the area. Then the node locations are set randomly within the previously determined area as shown in the following expressions:

$$
\begin{aligned}
& S(i) \cdot x_{d}=\operatorname{rand}(1,1) \times x_{m} \\
& S(i) \cdot y_{d}=\operatorname{rand}(1,1) \times y_{m}
\end{aligned}
$$

Where: $\mathrm{S}(\mathrm{i})$ : represents the node from 1 to $\mathrm{n}$

$$
\begin{gathered}
x_{d}: \text { denotes the distance from } \mathrm{x} \text { axis } \\
y_{d}: \text { denotes the distance from } \mathrm{y} \text { axis }
\end{gathered}
$$

Also the distance from the base station for each node is calculated as follows [13]:

$$
\text { distance }=\sqrt{\left(\left(S(i) \times x_{d}-S(n+1) \times x_{d}\right)\right)^{2}+\left(S(i) \times y_{d}-S(n+1) \times y_{d}\right)^{2}}
$$


Where: $n$ is the number of nodes from 1 to $n$

and $S(n+1)$ is the sink node

\subsection{Selection of cluster heads}

The cluster head collects data from the surrounding nodes and sends it to the base station. Initially the cluster head is selected randomly, after that the selection is based on the previous data collected and the location of the sensors as shown in the flowchart Figure 6 above.

\subsection{Node Time Slot}

Since the algorithm is based on reducing transmission of repetitive and useless data, the time slot is given to each node depends on the previous data. If the data is the same as the previous one, the node will be in a sleep state for a double time slot. If the data changed, then the time slot will be reduced by half as in the diagram shown in Figure 5.

\section{$7 \quad$ Simulation Results}

\subsection{DCRP versus Leach Protocols}

The performance of the DCRP is compared with LEACH and PRRP protocols. Figure 7 shows the comparison between DCRP and LEACH in terms of the number of live nodes versus number of rounds. It is clearly observed that the system using DCRP protocol has more live time than that for LEACH protocol. It is about $25 \%$.

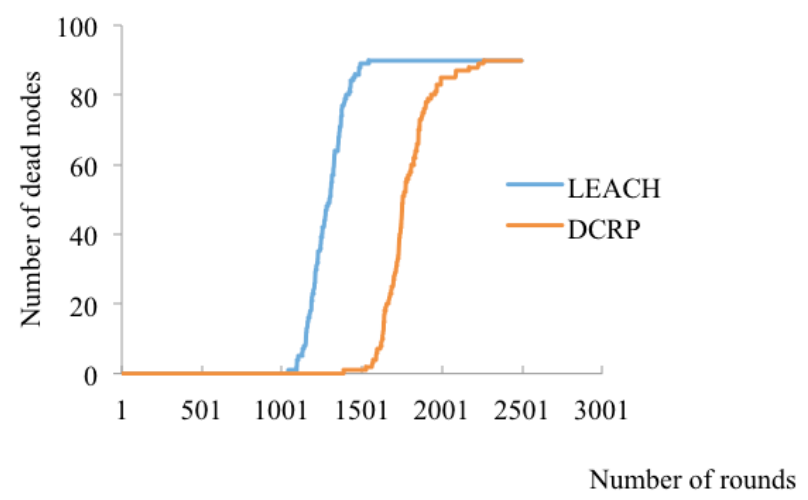

Fig. 7. Comparison between DCRP and LEACH

On the other hand the following Figure8 represents a sample of the results obtained to compare between DCRP and LEACH in terms of residual energy versus number of rounds. The results clearly indicate that the sensors using DCRP protocol have more 
residual energy compared to that used in LEACH protocol for the same number of rounds.

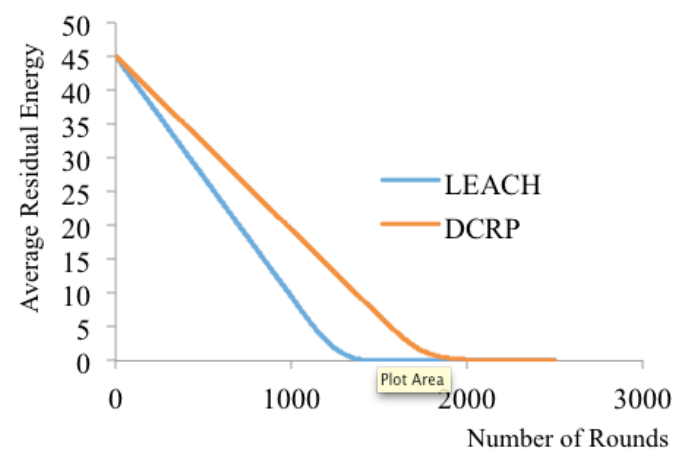

Fig. 8. Average Residual Energy versus rounds

\subsection{DCRP versus PRRP}

The proposed protocol is also compared with PRRP protocol. A couple of tests were carried for various parameters. Table 2 represents the data obtained for DCRP and PRRP protocols in terms of number of live nodes versus time and Figure 9 shows the graph comparison between DCRP and PRRP protocols in terms of number of live nodes. It clearly shows that the sensors implanted for DCRP protocol have more live time than those used for PRRP protocol.

On the other hand Table 3 represents the data obtained for the total energy consumed for both protocols with the corresponding graph shown in Figure10. It indicates that the total consumed energy in the system using DCRP protocol is less than the total energy consumed in the system using PRRP protocol for the same period.

Table 2. Data obtained for DCRP and PRRP protocols in terms of the number live nodes versus time

\begin{tabular}{|c|c|c|c|}
\hline Test No. & Round & PRRP & DCRP \\
\hline 1 & 50 & 200 & 200 \\
\hline 2 & 150 & 200 & 200 \\
\hline 3 & 250 & 200 & 200 \\
\hline 4 & 300 & 200 & 200 \\
\hline 5 & 350 & 200 & 199 \\
\hline 6 & 375 & 180 & 194 \\
\hline 7 & 390 & 155 & 184 \\
\hline 8 & 400 & 150 & 175 \\
\hline 9 & 450 & 10 & 84 \\
\hline 10 & 500 & 0 & 24 \\
\hline 11 & 550 & 0 & 14 \\
\hline 12 & 662 & 0 & 1 \\
\hline
\end{tabular}




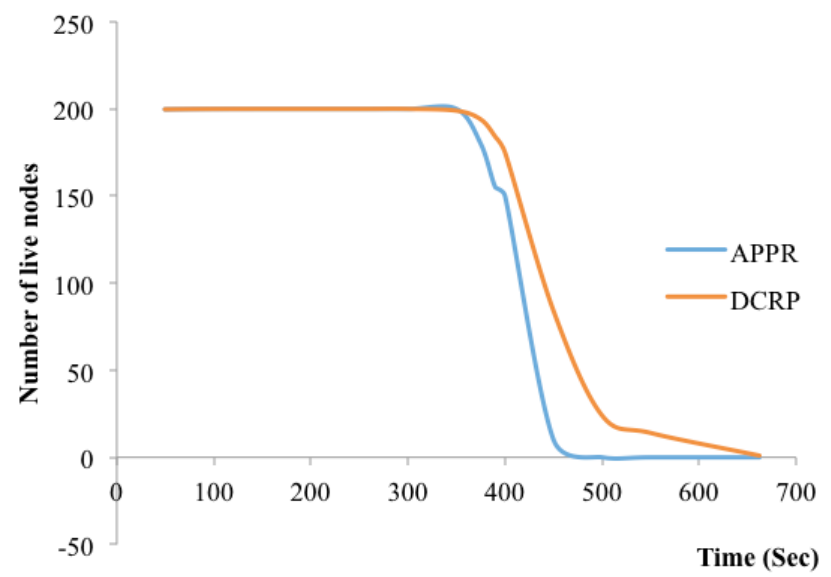

Fig. 9. Comparison between DCRP and PRRP protocols in terms of number of live nodes versus time.

Table 3. Total energy versus Time for DCRP and PRRP Protocols

\begin{tabular}{|c|c|c|c|}
\hline Test No. & Round & PRRP & DCRP \\
\hline 1 & 25 & 50 & 17 \\
\hline 2 & 50 & 100 & 34 \\
\hline 3 & 75 & 125 & 70 \\
\hline 4 & 150 & 150 & 101 \\
\hline 5 & 225 & 210 & 160 \\
\hline 6 & 250 & 250 & 168 \\
\hline 7 & 300 & 300 & 190 \\
\hline 8 & 350 & 325 & 235 \\
\hline 9 & 375 & 375 & 251 \\
\hline 10 & 400 & 400 & 267 \\
\hline
\end{tabular}

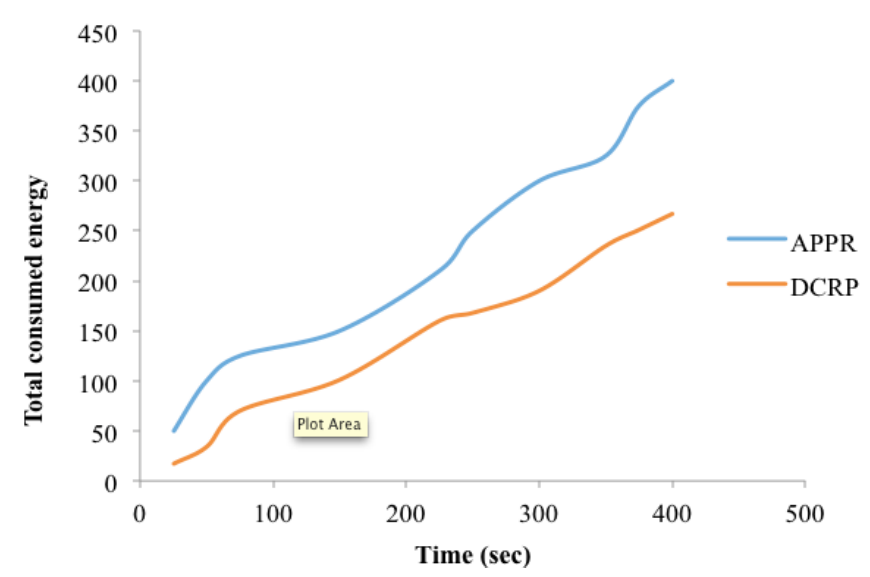

Fig. 10.Total consumed energy versus time for DCRP and PRRP protocols 


\section{Conclusion and Recommendations}

It could be concluded that: the results shown in the previous Figures clearly indicates that using data analysis in selecting cluster head and in time slot determination saves energy and thus improves the network lifetime. The level of improvement depends on the data itself and type of data being sensed; in the proposed protocol the simulation results showed the network lifetime is improved by more than $25 \%$ which is reasonably good compared to the results cited in the state of art.

The proposed works can be enhanced by implementing advanced artificial intelligence techniques to analyze the data obtained.

\section{Acknowledgement}

This work was financially supported by Deanship of Scientific Research (DSR), University of Tabuk, Tabuk, Kingdom of Saudi Arabia, under grant no. (S/1436/0221).

\section{References}

[1] S.Prasanna, Srinivasa Rao, An Overview of Wireless Sensor Networks Applications and Security, International Journal of Soft Computing and Engineering (IJSCE) ISSN: 22312307, Volume-2, Issue-2, May 2012

[2] Mohd Fauzi Othmana , Khairunnisa Shazalib, Wireless Sensor Network Applications: A Study in Environment Monitoring System, Procedia Engineering 41 ( 2012 ) $1204-1210$ 1877-7058 (C) 2012 Published by Elsevier Ltd. International Symposium on Robotics and Intelligent Sensors 2012 (IR IS 2012) https://doi.org/10.1016/j.proeng.2012.07.302

[3] Guobao Xu, Weiming Shen, and Xianbin Wang, "Applications of Wireless Sensor Networks in Marine Environment Monitoring: A Survey", Sensors 2014, 14, 16932-16954; https://doi.org/10.3390/s140916932

[4] Sheikh Azid, Bibhya Sharma, Krishna Raghuwaiya, Abinendra Chand, Sumeet Prasad, A Jacquier,"SMS BASED FLOOD MONITORING AND EARLY WARNING SYSTEM", VOL. 10, NO. 15, AUGUST 2015 ISSN 1819-6608 ARPN Journal of Engineering and Applied Sciences.

[5] V.V. Krzhizhanovskayaa,b,g,*, G.S. Shirshova,b, N.B. Melnikovaa,b,g, R.G. Bellemana , F.I. Rusadia , B.J. Broekhuijsenc, B.P. Gouldbyd, J. Lhommed, B. Balise , M. Bubake , A.L. Pyayta,f, I.I. Mokhovf, A.V. Ozhiginf, B. Langf, R.J. Meijera, Flood early warning system: design, implementation and computational modules", Procedia Computer Science 4 (2011) 106-115 International Conference on Computational Science, ICCS 2011 https://doi.org/10.1016/j.procs.2011.04.012

[6] David Culler, Berkeley Deborah Estrin Mani Srivastava, "Overview of Sensor Networks", Published by the IEEE Computer Society, 0018-9162/04/\$20.00 (C) 2004 IEEE August 2004.

[7] Shio Kumar Singh, M P Singh, and D K Singh, "Routing Protocols in Wireless Sensor Networks - A Survey", International Journal of Computer Science \& Engineering Survey (IJCSES) Vol.1, No.2, November 2010 https://doi.org/10.5121/ijcses.2010.1206

[8] R. Elankavi , R. Udayakumar, Kalaiprasath.R, "Data Collection in Wireless Sensor Networks - A Literature Survey", International Journal of Innovative Research in Computer- 
Paper-Data-Based Energy Efficient Clustered Routing Protocol for Wireless Sensors Networks

and Communication Engineering Vol. 1, Issue 5, July 2013 Copyright to IJIRCCE www.ijircce.com 1168

[9] Mohammad Hossein Anisi, Abdul Hanan Abdullah, Shukor Abd Razak, "WSN EnergyEfficient Data Collection in Wireless Sensor Networks", Wireless Sensor Network, 2011, 3, 329-333 Published Online October 2011 (http://www.SciRP.org/journal/wsn) Copyright (C) 2011 SciRes. https://doi.org/10.4236/wsn.2011.310036

[10] Sagar S De, Minati Mishra, Satchidananda Dehuri, "An architectural framework for knowledge extraction from meteorological data", International Journal of Applied Management Science, 2014, Vol. 6, isuue 4, p. 323-342.

[11] B.E. Pengel, V.V. Krz., N.B. Melnikova, G.S. Shirshov, A.R. Koelewijn, A.L. Pyayt, I.I. Mokhov, Flood Early Warning System: Sensors and Internet, published in IAHS Red Book N 357, Floods: From Risk to Opportunity. IAHS Publ. 357, 2013, pp. 445-453 http://iahs.info/redbooks/357.htm

[12] Edward N. Udo1, Etebong B. Isong, Flood Monitoring and Detection System using Wireless Sensor Network", Asian Journal of Computer and Information Systems (ISSN: 2321 5658) Volume 01- Issue 04, December 2013 Asian Online Journals (www.ajouronline.com) 108 .

[13] Sumithra S, Aruldoss Albert Victoire T, An energy efficient linear chain-based clustering routing protocol for wireless, sensor networks, Journal of theoretical and applied information technology, 31 st may 2014. vol. 63 no.3.

[14] Heinzelman, W., Chandrakasan, A., and Balakrishnan, H., "Energy-Efficient Communication Protocols for Wireless Microsensor Networks", Proceedings of the 33rd Hawaaian International Conference on Systems Science (HICSS), January 2000. https://doi.org/10.1109/HICSS.2000.926982

[15] Noor Zaman, Abdullah A., Position Responsive Routing Protocol (PRRP), 13th International Conference on Advanced Communication Technology (ICACT), Seoul, South Korea, 2011.

[16] Gautam N, Lee Wong, Pyun, Jae-Young, Track-Sector Clustering for Energy Efficient Routing in Wireless Sensor Networks. CIT ' 09 Ninth IEEE International Conference on Computer and Information Technology, Xiamen, China, China, 2009.

[17] Minh Tuan Nguyen, Keith A. Teague, Nazanin Rahnavard. CCS: Energy-efficient data collection in clustered wireless sensor networks utilizing block-wise compressive sensing. Computer Networks 106 171-185. 2016. https://doi.org/10.1016/j.comnet.2016.06.029

[18] Arati Manjeshwar, Dharma P. Agrawal. APTEEN: A Hybrid Protocol for Efficient Routing and Comprehensive Information Retrieval in Wireless SensorNetworks. Proceedings of the 16th International Parallel and Distributed Processing Symposium. Washington, DC, USA. 2002. https://doi.org/10.1109/IPDPS.2002.1016600

[19] Eyad Abushandi, Flood prevention dams for arid regions at a micro scale sub-catchment, case study: Tabuk, Saudi Arabia. Water Science \& Technology 74(11) · July 2016

[20] Eyad Abushandi, Flash flood simulation for Tabuk City catchment, Saudi Arabia. Arabian Journal of Geosciences 9(3) · March 2016.

\section{Authors}

Ammar E. Babiker, Mohamed A. A. EImaleeh, Onaytra Abbas, and Abdelrahman Osman Elfaki are with Faculty of computers and Information Technology, University of Tabuk, Tabuk, Saudi Arabia (a.elfaki@ut.edu.sa).

Article submitted 03 August 2017. Published as resubmitted by the authors 15 September 2017. 